
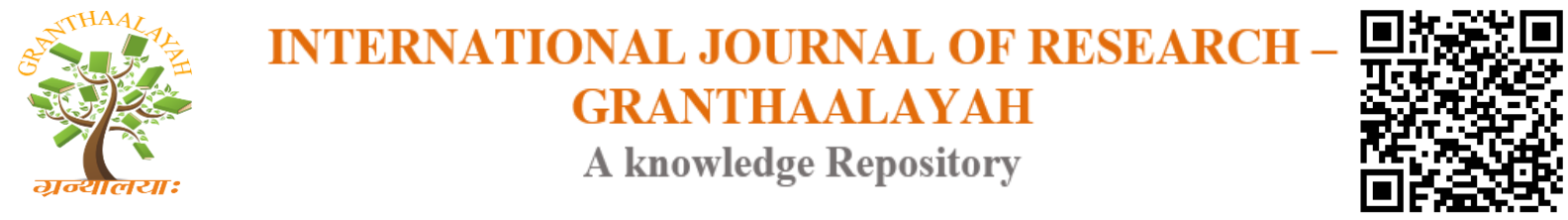

Science

\title{
OCCUPATIONAL HAZARDS IN CONSTRUCTION INDUSTRY: CASE STUDIES FROM HOUSING AND CONSTRUCTION WORKERS AT ADDIS ABABA, ETHIOPIA
}

\author{
Thewodros Bekele Tolera *1 \\ ${ }^{* 1}$ Center for Environmental Science, Addis Ababa University, Po box 1176, ETHIOPIA
}

DOI: https://doi.org/10.29121/granthaalayah.v4.i9.2016.2539

\section{ABSTRACT}

The status of occupational injuries in workplaces in general is ill defined in Ethiopia. Pocket studies indicate that occupational injury due to an unsafe working environment is increasing. Construction industries are growing industries region wise that has higher rate of workrelated injuries. Knowing the associated factors of work-related injuries can be a critical step for improving the working condition of workers in the sector.

Objective: This mini research aimed to evaluate occupational hazards and to describe factors affecting its happening among construction workers' in Addis Ababa housing and construction project sites.

Institutional based cross-sectional study design was employed to assess occupational injuries among randomly selected construction workers from June 30 -July 20, 2014. A structured questionnaire based interviews, work environment observation were used to collect the data.

The response rate of this study was $82.7 \%$. The majority of respondents were male which account $74.7 \%$ and $60(96.8 \%)$ respondents were not using personal protective devices all the time while they are on duty. Out of the total participants, $67.7 \%$ of the workers experienced occupational injuries at least once in the last 12 months. Moreover, the three leading cause of injuries were puncture (21.0\%) followed by hand injury (11.3\%), and back pain (9.7\%).

Increased rate of work related injury in construction workers was observed and implementation of basic occupational health and safety services is required together with regular supervision to ensure and promote work place safety. So Preventive measures concerning functional occupational health and safety programs are essential to safeguard the health and safety condition of workforce in construction industries.

Keywords:

Construction workers; Occupational injuries; Personal protective devices; Ethiopia.

Cite This Article: Thewodros Bekele Tolera, "OCCUPATIONAL HAZARDS IN CONSTRUCTION INDUSTRY: CASE STUDIES FROM HOUSING AND CONSTRUCTION WORKERS AT ADDIS ABABA, ETHIOPIA" International Journal of Research Granthaalayah, Vol. 4, No. 9 (2016): 84-96. 


\section{INTRODUCTION}

The construction industry is a sector of the economy that transforms various resources into constructed physical economic and social infrastructure necessary for socio-economic development. It embraces the process by which the said physical infrastructure are planned, designed, procured, constructed or produced, altered, repaired, maintained, and demolished. Construction industries employing a large number of people on its workforce meeting the demands of rapidly growing economies as well as requirements for normal building, renovation, maintenance and natural calamities in all countries. Due to the advent of industrialization and recent developments, this industry is taking a pivotal role for construction of buildings, roads, bridges, and so forth.

Injuries related to construction work remain a serious problem worldwide. The International Labor Office (ILO) estimates that every year there are some 125 million work related accidents, 220000 of them fatal. According to WHO, 160 million new cases of occupational diseases are caused annually by exposure and dangerous conditions at the work place; $30-40 \%$ of them can be expected to lead to chronic diseases and about $10 \%$ are likely to result in permanent disability. Every nine minutes, someone is killed by their job. In 1994, employers reported 6.3million disabling work injuries and 515000cases of occupational diseases [6]. Annually, throughout the world, an estimated 271 million people suffer from work related injuries, and 2 million die from these injuries.Worldwide as it has been estimated in 2005, 250 million occupational injuries and 5.4 million deaths due to injuries occurred annually. From this, over 90 percent was in low- and middle income countries where the greatest concentration of world's workforce and low level of factories found [3-4].

Although many prevention efforts and intervention programs have been undertaken [5, 6], it is a known fact that construction workers continue to carry a particularly high risk of sustaining fatal and nonfatal injuries. In most countries throughout the world the construction industry continues to account for a disturbingly high proportion of fatal and nonfatal injuries [8]. The International Labor Organization (ILO) estimates that more than 100,000 construction workers around the world die every year - that is one person every five minutes [7].

For instance, the construction industry is one of the largest industries in the United States, employing over eleven million persons representing 8\% of the total labor force [9-11]. Each year, several hundred thousand construction workers become ill or injured as a result of worksite hazards. The estimated rates for injuries, illnesses, and fatalities among construction workers are consistently among the highest of any occupational sector [12]. Construction hazards are rated as eight times more risky as those from manufacturing sector [28].

Occupational injuries pose a major public health and developmental problems; which result in a serious health, social and economic consequences on workers and their employers. Investigators at different places indicated that younger workers suffer more occupational injury at a higher rate than older workers. Most occupational health and safety studies conducted in developed countries revealed that increased educational levels in the factory have been associated with decreased work-related injuries [13-18]. But lack of training, sleeping disturbance, and job stress increased the risk of occupational injury. Poor perception regarding to working conditions and 
safety environment had a significant influence on injury occurrence [19]. Work burden as working more than $48 \mathrm{hrs} /$ week, handling objects greater than $20 \mathrm{~kg}$, visual concentration, and timely maintenance of machine and sleep disorder were significant factors for the occurrence of occupational injuries in industries [20]. Construction work is featured by high labor turnover, constantly changing work environment and conditions on site, and different types of work being carried out simultaneously by several contractors. These features would further increase the health risks of workers [24].

Even though, safety management in construction industry indeed is a challenging task due to the dynamic nature of construction activity coupled with involvement of unskilled, illiterate and mobile work force, some regions have been making progress over the years there is still a long way to go to reach the vision of an industry where people return home at the end of a shift healthier than when they arrived [22].

Ethiopia, is striving hard to improve its basic amenities by building schools, hospitals, housing complexes, shops, offices, highways, power plants, industries, bridges and other infrastructures. However, all these construction activities are carried out by unskilled labor forces at cheap rate. Occupational injuries and accidents among these workers are high due to illiteracy, poverty, lack of health and safety training and information on health hazards and risks at the work place.

The Construction Industry Policy (CIP) of Ethiopia aimed at creating an enabling environment for the development of a vibrant, efficient and sustainable local industry that meets the demand for its services to support sustainable economic and social development objectives. The construction sector has showing its increased percentage share to the country GDP at constant basic price from $4.3 \%$ in 1993 E.C to $5.8 \%$ by 2002 E.C [23]. In the meantime, the status of occupational injuries in workplaces in general is ill defined in Ethiopia and some pocket studies indicated that occupational injury due to an unsafe working environment is increasing.

In line with this, little work has been done on occupational health and safety aspects of building construction workers and as per literature review there is lack of data about prevalence and determinant factors of occupational injuries among these workers [25]. Knowing the associated factors of work-related injuries can be a critical step for improving the working condition of workers in the sector [1\&2].

Briefing the current occupational risks and problems in relation to construction industry and safety at selected construction sector;

The research question is

- How many of construction workers using protective instruments?

- What is the status of hazard management in construction industry?

- What type of accidents workers have faced so far in construction site?

Addressing the research question the overall aim of the study is to evaluate the potential hazards of construction workers towards occupational safety and health administration measures that are employed at the workplace. Hence the objective of the study was to:-

- evaluate the status of hazard management in the building construction industry

- assess the type of accidents workers have faced so far in the construction industry 
- Observe the workers' level of care in securing their personal safety and health in the workplace

\section{MATERIALS AND METHODS}

The study evaluates the status of safety and health perceptions of construction workers at the workplace. Both qualitative and quantitative data has been collected by interviews, questionnaires and observations were used. The sampling of the population was done by systematic stratified random sampling involving the various business units of the construction industry.

\section{STUDY AREA AND DESIGN}

A descriptive institution based cross-sectional study was conducted from June 30 -July 20, 2014; among construction workers at constriction and housing project site 13 and 14 in Yeka Sub city, Abado woreda.

\section{STUDY AREA}

The study area (project site) is located on the North East tip of the city of Addis in Legetafo area along the Dessie road. The site is not at all developed being used for farming exercise until recent times, except for a small area settlement at the entry point to the site. The project area has covered about 100ha and it is one of the mega housing and construction project run by Addis Ababa City administration which planned to construct 538 blocks that contain 8316 households.

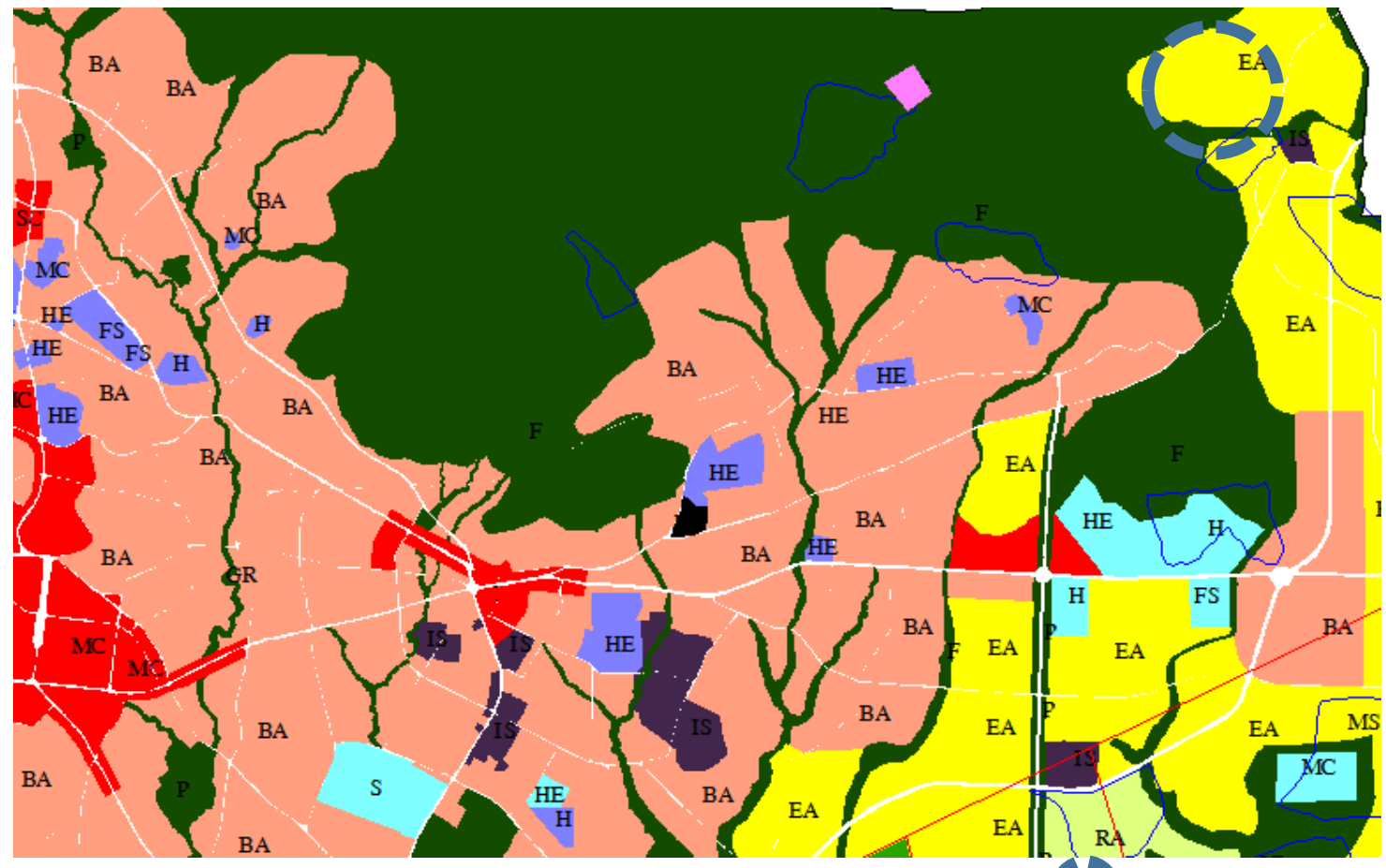

Figure 1: Land use map according to the master plan Source: BET Consulting Architects and Engineers Built Environment Technlology plc 


\section{SOURCE POPULATION}

All construction employees who are involved in the Yeka Abado Addis Ababa housing construction project site 13 and 14 were considered as a source population and the required sample size were taken from this population.

\section{STUDY POPULATION}

The selected samples in the construction site were considered as the study population and all the require information were collected from these population. A total of 750 workers were involved in a particular contractor at a given construction site. Based upon the job description $10 \%$ of samples were taken, the study populations were stratified in to nine different strata i.e. Daily laborer, Plasterer, Carpenter, Manson, Welder, Painter, General Forman, Bar bender and Site Engineer. The number of samples from each stratum was done proportionally. Finally, simple random sampling technique was employed to select 75 sample sizes from the strata.

\section{OPERATIONAL DEFINITION}

Occupational Injury: Any physical injury condition sustained on worker in connection with the performance of his or her work in construction site [26]

Health and Safety Information: A worker who have got any kind of information in-one-year period through any kind of media about health and safety of construction workers

Health and Safety Training: Trainings given to a worker about health and safety to construction workers

Personal Protective Equipment (PPE): Utilization of the worker-specialized clothing or equipment worn by employees for protection against health and safety hazards at the time of interview.

\section{DATA COLLECTION PROCEDURE}

Both quantitative and qualitative data has been collected by structured questionnaire, consisting of both closed and open-ended questions and by in depth interview. The data were collected by using the "Amharic" version of the questionnaire. Detailed information about the sociodemographic, behavioral and work environment characteristics, awareness and practice towards occupational health among construction workers and episodes of injuries in the past one year were collected.

\section{DATA ANALYSIS}

The data were entered, cleaned and analyzed using SPSS software version 16.0. Descriptive statistics like frequency distribution mean and percentage calculation was made for most of the variables. 


\section{ETHICAL CLEARANCE}

Permission was also obtained from the local administrative bodies (Addis Ababa City housing and construction Authority) and concerned construction companies. Verbal consent was also obtained from every study subject after clearly explained the purpose of the study.

\section{RESULTS AND DISCUSSION}

\section{QUANTITATIVE RESULT}

\section{Characteristics of the study population}

75 randomly selected building construction workers in questionnaire and 8 workers from foremen, site engineer's, consultant and human resource personnel for interview participated (83 total) in the study yielding $82.7 \%$ response rate. The majority of respondents were male which account $74.7 \%$ and $67.7 \%$ of the respondents get monthly salary below 1000 Ethiopian birr. Sixty one $(98.4 \%)$ of the respondents was working 8 hours per day. Most of the respondents $77.7 \%$ of them were youths having age less than 26 years of age with relatively closer percent (77.4\%) primary school and above educational status (see Table 1).

\section{Work Environment and behavioral factors}

Only $2(3.2 \%)$ of respondents used some kinds of personal protective equipment's (PPE) while they are on duty. Most of the respondents 60 (96.8\%) of them were not using PPE all the time while they are on duty. The main reasons mentioned by the respondents for none use of PPE were; no access 58 (93.5\%), discomfort 4 (6.5\%). All of the partial users of PPE, $2(3.2 \%)$ purchase PPEs for themselves (See Table 2).

Table 1: Socio-demographic characteristic of the respondents at Yeka Abado housing construction project Site13 and 14 July 2014, Addis Ababa $(n=75)$.

\begin{tabular}{|lll|}
\hline Variable & Frequency & Percentage (\%) \\
\hline Residence & & \\
\hline Urban & 46 & 74.2 \\
\hline Rural & 16 & 25.8 \\
\hline Sex & & \\
\hline Male & 56 & 74.7 \\
\hline Female & 19 & 25.3 \\
\hline Age(years) & & \\
\hline$<20$ & 8 & 12.9 \\
\hline $20-25$ & 34 & 54.8 \\
\hline $26-30$ & 18 & 29 \\
\hline $31-35$ & 1 & 1.6 \\
\hline Marital Status & & 66.1 \\
\hline Married & 41 & 30.6 \\
\hline Single & 19 & 3.2 \\
\hline Divorced & 2 & 11.3 \\
\hline Educational status & & \\
\hline Illiterate & 7 & \\
\hline
\end{tabular}




\begin{tabular}{|lll|}
\hline Can read \&write & 7 & 11.3 \\
\hline Primary School (1-8) & 33 & 53.2 \\
\hline Secondary School(9-10) & 15 & 24.2 \\
\hline Employment pattern & & \\
\hline Permanent & 1 & 1.6 \\
\hline Temporary & 61 & 98.4 \\
\hline Working sections (job category) & & \\
\hline Daily laborer & 25 & 33.3 \\
\hline Bar bender & 11 & 14.7 \\
\hline Plasterer & 7 & 9.3 \\
\hline Carpenter & 11 & 14.7 \\
\hline Manson & 9 & 12.0 \\
\hline Welder & 4 & 5.3 \\
\hline Painter & 8 & 10.7 \\
\hline Service Years & & 33.9 \\
\hline$<$ 1year & 21 & 54.8 \\
\hline $1-5$ years & 34 & 11.3 \\
\hline$>5$ years & 7 & \\
\hline
\end{tabular}

Majority of the workers $(90.3 \%)$ perform their work without having any job agreement with the respective employer. But most of the workers (77.4) are satisfied being on duty at construction site (see Table 2).

Table 2: Selected work environment and behavioral factors at Yeka Abado housing construction project Site13 and 14 July 2014, Addis Ababa (n=62)

\begin{tabular}{|l|l|l|}
\hline Variable & Frequency & Percentage (\%) \\
\hline Hours worked/week & & \\
\hline 48 hours & $\mathbf{6 1}$ & $\mathbf{9 8 . 4}$ \\
\hline$>48$ hours & $\mathbf{1}$ & $\mathbf{1 . 6}$ \\
\hline Health and Safety Trainings & & \\
\hline Yes & $\mathbf{0}$ & \\
\hline No & $\mathbf{6 2}$ & $\mathbf{1 0 0}$ \\
\hline Work agreement & & \\
\hline Yes & $\mathbf{6}$ & $\mathbf{9 . 7}$ \\
\hline No & $\mathbf{5 6}$ & $\mathbf{9 0 . 3}$ \\
\hline Monthly Salary in Ethiopian Birr* & & \\
\hline$<1000$ & $\mathbf{4 2}$ & $\mathbf{6 7 . 7}$ \\
\hline$>1000-<2000$ & $\mathbf{1 5}$ & $\mathbf{2 4 . 2}$ \\
\hline$>2000-<3000$ & $\mathbf{5}$ & $\mathbf{8 . 1}$ \\
\hline Job satisfaction & & \\
\hline$Y e s$ & $\mathbf{4 8}$ & $\mathbf{7 7 . 4}$ \\
\hline No & $\mathbf{1 4}$ & $\mathbf{2 2 . 6}$ \\
\hline Using PPE & & \\
\hline$Y e s$ & $\mathbf{2}$ & $\mathbf{3 . 2}$ \\
\hline No & $\mathbf{6 0}$ & $\mathbf{9 6 . 8}$ \\
\hline Awareness on occupational risk & & \\
\hline$Y e s$ & $\mathbf{5 5}$ & $\mathbf{8 8 . 7}$ \\
\hline No & $\mathbf{7}$ & $\mathbf{1 1 . 3}$ \\
\hline & & \\
\hline
\end{tabular}




\begin{tabular}{|l|l|l|}
\hline Reasons not using PPE & & \\
\hline Not provided & $\mathbf{5 8}$ & $\mathbf{9 3 . 5}$ \\
\hline Unsuitable for work & $\mathbf{4}$ & $\mathbf{6 . 5}$ \\
\hline
\end{tabular}

*1US\$ is equivalent to 21.7ETH birr

\section{Occupational injury Characteristics}

Table 3: Injury types and causes at Yeka Abado housing construction project site13/14 July 2014, Addis Ababa ( $n=62)$

\begin{tabular}{|l|l|l|}
\hline Variable & Frequency & Percentage (\%) \\
\hline $\begin{array}{l}\text { Occupational injuries Types of } \\
\text { injury(n=62) }\end{array}$ & & \\
\hline Fracture & $\mathbf{1}$ & $\mathbf{1 . 6}$ \\
\hline Eye injury & $\mathbf{3}$ & $\mathbf{4 . 8}$ \\
\hline Back pain & $\mathbf{6}$ & $\mathbf{9 . 7}$ \\
\hline Cuts & $\mathbf{4}$ & $\mathbf{6 . 5}$ \\
\hline Puncture & $\mathbf{1 3}$ & $\mathbf{2 1}$ \\
\hline Crushing & $\mathbf{4}$ & $\mathbf{6 . 5}$ \\
\hline Hand injury & $\mathbf{7}$ & $\mathbf{1 1 . 3}$ \\
\hline Suffocation & $\mathbf{2}$ & $\mathbf{3 . 2}$ \\
\hline Respiratory infection & $\mathbf{2}$ & $\mathbf{3 . 2}$ \\
\hline Causes of Occupational injuries $(n=62)$ & & \\
\hline Stuck by/against an object & $\mathbf{2}$ & $\mathbf{3 . 2}$ \\
\hline Hit by falling object & $\mathbf{1}$ & $\mathbf{1 . 6}$ \\
\hline Falling accident & $\mathbf{4}$ & $\mathbf{6 . 5}$ \\
\hline Absence of protective devices & $\mathbf{2 5}$ & $\mathbf{4 0 . 3}$ \\
\hline Work burden & $\mathbf{5}$ & $\mathbf{8 . 1}$ \\
\hline Lifting heavy objects & $\mathbf{5}$ & $\mathbf{8 . 1}$ \\
\hline
\end{tabular}

\section{QUALITATIVE RESULT}

\section{Work Environment Observation}

In depth interviews were conducted on purposely selected individuals (foramens, site engineer's, consultants, human resource managers) in the housing construction site 13 and 14. Most of the participants having more than three years of working experience in the construction sector. The most common reported occupational symptoms of disease were encountered in the construction site were "...falling accident as a result death, fracture, fatigue, back pain, abdominal crump, cough, skin problem, skin puncture, irritation of the eye and nose".

\section{Hygienic related issues}

The other reported issue is the quality of available water and toilets in the project sites. There were only two toilets one for the construction workers and on other for administration workers. But there is no any quality water for the workers for drinking, showering and for other purposes as well. Little effort has been done to help construction workers to take care of their hygiene. 


\section{Factors for health symptoms (Hazards)}

Among the Interviewed subjects, mentioned that "Most health problems occur because of absence of protective devices in the work area, the primarily lack of the practicality of safety rules".

\section{Prevention of hazards}

There are limited trials to address the hazard prevention activities in the working conditions at construction, like giving PPE (Hard hat and safety shoes) to the site engineers; Some trainings on occupational health and safety at Addis Ababa city administration management institute; however, this trial is seems at infancy stage because for reasons such as an absence of unions and strong management support... To reach the desired level of prevention to protect workers adequately

\section{Pre-employment safety training}

Considering new employees, equipment and other changes in general, there is no formal preemployment safety training except that of site engineers some office workers. The obtained data reveals that there is no occupational health and safety committee; no trainings were given to the workers when they were newly employed or as refreshment. Either Ministry of Labor and Social affairs or Ministry of Health undergo regular work area supervision.

The working environmental observation check list showed that, there were no any safety signs and rules posted like danger sign. Most of the workers did not have the necessary personal protective equipment. There was no any measure taken to prevent hazards, except providing safety shoes, protective cups to some of the site engineers. There is no any copy of most important safety and health regulation in the consultants and they did not have safety personnel. Even though, both agreed to the prevalence of risks in construction site; the consultants as well as the city administration were not following written health and safety plan of action in work place in general. There was no health facility in the construction site. Even it is hard to get first aid kit.

\section{DISCUSSIONS}

In Addis Ababa currently there are about 254 construction consultants from level 1 to 6 and 1355 construction contractors who engaged as a professional in construction industry. They have got working license from Addis Ababa city housing and construction authority by fulfilling the outlined requirements. But in the requirements nothing is expected from these firms with respect to Occupational safety and hygiene. On contrary the Ethiopian Labor proclamation No 377/06 in Article 92 clearly spells out the fundamental obligations of an employer with regard to putting in place of all the necessary measures in order to ensure, work places are safe, healthy and free of any danger to the well-being of workers. Moreover, the proclamation ensure that workers are properly instructed and notified concerning the hazards of their respective occupations and the pre cautions necessary to avoid accident $\&$ injury to health. Ensure that directive are given and also assign safety officer, establishes an occupational, safety and health committee, provides workers with protective equipment, clothing and other materials and instruct them of its use, obliged to register and notify to the nearest labor inspection services occupational accident and diseases [30]. This is not practical in the study site. The study results revealed that out of total participants $67.7 \%$ of the workers experienced occupational injuries at least once in the last 12 
months. This finding was markedly higher than that of the study done in Ethiopia, and India $38.7 \%, 22.92 \%$ respectively $[25,29]$. The difference between the two might be associated to type of workforce, strengths of occupational health and safety services and diversity and complexity of work tasks, or difference in the method of data collection.

The three leading occupational injuries in the study site were puncture $(21.0 \%)$ followed by hand injury $(11.3 \%)$, and back pain $(9.7 \%)$. The major possible causes reported as absence of protective devices $(40.3 \%)$, lifting heavy objects $(8.1 \%)$ and work burden $(8.1 \%)$ This result vary with the study conducted at Gondar [25] on which the leading causes of injuries were fall from ground level followed by overexertion during lifting and fall from elevation.

Almost all workers unable to use $(96.8 \%)$ because they were unable to get protective devices from the organization (93.5\%) or absence of occupational health trainings (100\%) see Table 2. This might be associated to lack of awareness, stringent commitment on the issue, or legal controlling mechanisms of construction sector even the consultants and contractors get working license or renew it without such basic requirements of occupational safety and hygiene issue in the work place.

\section{LIMITATIONS OF THE STUDY}

1) Across-sectional study (few sample size) design could result in recall bias (under or over report of Injury events) and /or may be weaker to overlook the potential problems ever occurred in detail and determinants.

2) Sometimes the study units were not willing to disclose the whole problems in fear of job insecurity following disclosing the information.

3) Workers who were injured and on leave during the study time may underestimate any association.

4) Lack of similar studies particularly in Ethiopia made difficult in comparing results

5) The result may be inflated, due to respondents' positive benefit feeling after the study finding

\section{CONCLUSION}

Work-related injury prevention and control involves studying the patterns and risk factors of injuries. So the results of this study have important implications for the practice of occupational health and safety, especially in industries or occupational groups dealing with safety information. $82.7 \%$ response rate of study results revealed that out of total participants $67.7 \%$ of the workers experienced occupational injuries at least once last 12 months. Moreover, the three leading cause of injuries were puncture $(21.0 \%)$ followed by hand injury $(11.3 \%)$, and back pain $(9.7 \%)$.

Majority of the respondents were unable to use PPE (96.8\%) in the working environment. This is because they were unable to get protective devices from the organization (93.5\%) and unable to buy it by themselves. The absence of occupational health trainings (100\%) reveals that, the extent of occupational injuries among Addis Ababa city housing and construction project workers of project site 13/14 in Yeka Abado, needs immediate public health action. Therefore, implementation of basic occupational health and safety services including the provision of personal protective devices and insuring utilization are highly advisable. 
Based on the above findings and conclusions for sustained prevention and control of work related injuries in construction site, the following recommendations are made for action:

- Provide appropriate health and safety training for workers, beginning with the first day of their employment.

- Strength strict supervision of workplace and working conditions.

- Establish active and functional health and safety programs.

\section{ACKNOWLEDGEMENTS}

I would like to express my gratitude and deep appreciation to Kefyalew Belayneh, ZereaYakob Aber, Endalkachew Tafa, Shewangizaw W/ mariyam, Brihanu Negash, Eshetu Hailu, Eyoel, Germs at project site 13/14.Dr.Mamo Wubshet.

\section{REFERENCES}

[1] Vad M M and Kines P(2011). Construction workers' perception and use of assistive devices in regards to musculoskeletal deterioration: a qualitative study; Safety Science monitor issue 3 articles 2 volume 15.

[2] Osman Yiha, Abera Kumie (2010). Assessment of occupational injuries in Tendaho Agricultural Development S.C, Afar Regional State, Ethiop. J. Health Dev.;24(3):167174.

[3] Igor A. Fedotov (1998). World Health Forum, An international journal of health development. Vol. 19(4), pp.390-396, WHO, Geneva.

[4] WHO/ILO (1987). Occupational Health and Safety in Africa. Meeting report on occupational health hazard.

[5] Lehtola MM, van der Molen HF, Lappalainen J, et al., (2008). The Effectiveness of Interventions for Preventing Injuries in the Construction Industry: A Systematic Review. American Journal of Preventive Medicine, 35:77-85.

[6] Rivara FP, Thompson DC (2000). Prevention of falls in the construction industry: Evidence for program effectiveness. American Journal of Preventive Medicine, 18:23-26.

[7] International Labour Organization (2010). The role of worker representation and consultation in managing health and safety in the construction industry. Geneva.

[8] Pedersen, B H., Hannerz, H., Christensen, U. and Tüchsen, F.(2011). Enterprise size and risk of hospital treated injuries among manual construction workers in Denmark: a study protocol. Journal of Occupational Medicine and Toxicology 6:11.

[9] Lehtola MM, van der Molen HF, Lappalainen J, Hoonakker PL, Hsiao H, Haslam RA, Hale AR, Verbeek JH(2008). The effectiveness of interventions for preventing injuries in the construction industry: a systematic review. Am J Prev Med 2008, 35:77-85.

[10] van der Molen HF, Lehtola MM, Lappalainen J, Hoonakker PL, Hsiao H, Haslam R, Hale AR, Verbeek J(2007). Interventions for preventing injuries in the construction industry. Cochrane Database Syst Rev 2007, 17:CD006251.

[11] Centers for Disease Control and Prevention (2009). National Institute for Occupational Safety and Health (NIOSH) fact sheets: Construction worker safety and health. Atlanta, GA. U.S. Department of Health and Human Services, Centers for Disease Control and Prevention; 2010 [http://www.cdc. gov/niosh/topics/construction/]. 
[12] Friedman LS, Forst LS (2009). Workers compensation costs among construction workers: a robust regression analysis. J Occup Environ Med, 51:1306-1313.

[13] Rhys, D. and Paul, J. (2005). Trends and context to rates of workplace injury: Health and safety executive. Warwick Institute for Employment Research University of Warwick Coventry.

[14] Smith, P. M. and Mustard, C. A. (2004). Examining the associations between physical work demands and work injury rates between men and women: Occupational and Environmental Medicine, vol. 61, no. 9, pp. 750-756.

[15] Takele Tadesse and Abera. Kumie (2007). Prevalence and factors affecting work and work related injury among small and medium scale industries in Gondar woreda: Ethiopian Journal of Health Development, vol. 21, no. 1, pp. 25-34.

[16] Fulle A (1988). Injuries in urban factories of ketena one, Addis Ababa, M.S. thesis, Addis Ababa University unpublished.

[17] Asim, S, Takiar, R, Ramendra et al., (2004). An accident-risk assessment study of temporary piece rate workers Occupational Medicine Division, National Institute of Occupational Health. India: Industrial Health, vol. 42, no. 2, pp. 240-245, 2004.

[18] Nearkasen, C., Marie, J. M., Lahoucine B. and et al., (2002). Relationships between some individual characteristics and occupational accidents in the construction industry: $a$ case-control study: Journal of Occupational Health, vol. 44, no. 3, pp. 131-139.

[19] Zewdie Aderaw, Dagnew Engdaw, and Takele Tadesse (2011). Determinants of Occupational Injury: A Case Control Study among Textile Factory Workers in Amhara Regional State, Ethiopia Journal of Tropical Medicine Volume 2011, Article ID 657275, doi:10.1155/2011/657275.

[20] Yessuf Serkalem S, Moges Haimanot G, Ahmed Ansha N (2014). Determinants of occupational injury in Kombolcha textile factory, North-East Ethiopia. Int J Occup Environ Med 2014; 5(2):84-93. www.theijoem.com

[21] Tiwary and Gangopadhyay (2011). Occupational health \& social security of unorganized workers in construction Industry, Indian Journal of Occupational and Environmental Medicine - April 2011 - Volume 15 - Issue 1 Website: www.ijoem.com , DOI: 10.4103/0019-5278.83003.

[22] Aoife Finneran, Alistair Gibb (2013). W099 - Safety and Health in Construction Research Roadmap - Report for Consultation, CIB Publication 376.

[23] Ministry of Urban Development and Construction (2012). Construction industry policy(first draft)

[24] Occupational Safety and Health Branch (2004). Department Guidance Notes on Health Hazards in Construction Work, published by the Labor Department. http://www.labour.gov.hk/eng/public/oh/OHB82.pdf. Hong Kong.

[25] Mesafint Molla, Kassahun Alemu, Getahun Kebede, Sharma HR, Walelign Worku (2013). Occupational Injuries Among Building Construction Workers in Gondar City, Ethiopia. Occup Med Health Aff 1: 125. doi: 10.4172/2329-6879.1000125.

[26] Rhys, D and Paul, J.(2005).Trends and context to rates of workplace injury, Health and safety executive. Warwick Institute for Employment Research University of Warwick Coventry.

[27] Nearkasen, J. M. Marie, B. Lahoucine et al., (2002). Relationships between some individual characteristics and occupational accidents in the construction industry: $a$ case-control study; Journal of Occupational Health, vol. 44, no. 3, pp. 131-139. 
[28] Jain, S. K. (2007). Meeting the Challenges in Industrial Safety Management in Construction Works, Chairman \& Managing Director Nuclear Power Corporation of India Limited Anushaktinagar, Mumbai 400094

[29] Shah CK and Mehta H (2009). Study of Injuries among Construction Workers in Ahmeda bad City, Gujarat, Vol. 5, No. 6 ISSN: 0973-516X.

[30] MoLSA (2006). Ministry of Labor and social Affairs, Occupational safety and health profile for Ethiopia, Compiled by: Dawit Seblework(ILO Consultant).

[31] Labor proclamation No 377/2003 FDRE, house of representative, Year 10 No 12 ,2004, Addis Ababa. 